\title{
The Influence of Consumer Finance on the Second Child Needs of the Family
}

\author{
ZHOU Xiaowei \\ Shaanxi Normal University \\ International Business School \\ Xi'an, China \\ E-mail: xiaowei@snnu.edu.cn
}

\author{
LIU Fang \\ Shaanxi Normal University \\ International Business School \\ Xi'an, China \\ E-mail:717624399@qq.com
}

\begin{abstract}
Consumer finance is an important research field in economics and finance. With the implementation of two-child policy in China, consumer finance plays a more and more important role in the allocation of personal or family resources. The development of consumer finance has become an important factor in the demand of two children. The purpose of this paper is to discuss the basic categories and main issues of consumer finance and summarize the development of consumer finance in China. On this basis, from the angles such as family financial activities, consumer behavior, consumer finance, the financial market, as well as the relationship between the government and other aspects under consideration, further combining with the actual situation in China for the implementation of universal two-child policy, this paper puts forward the research direction of the two-child policy in China's consumer finance field.
\end{abstract}

Keywords-Consume; Consumer finance; Consumer behavior; Universal two-child policy

\section{INTRODUCTION}

Consumption means the use of social products and services to meet the needs of the people, and is the basic content and purpose of economic activities and development. The core issue of finance is the optimal allocation of resources or wealth over time. On the one hand, the purpose of allocating resources is to increase wealth and satisfy people's consumption. Obviously, the former's ultimate goal is to serve the latter. Therefore, consumer finance is the basic concern of finance. At the same time, consumer finance is closely related to quality of life and subjective well-being, and plays an important role in life and social field. With the emergence of the party's "two child" policy in the third Plenary Session of the 18th CPC Central Committee, the implementation of the 2016 comprehensive two - child policy has brought opportunities and challenges to the social and economic development of our country. Whether the birth of the two child is a choice of individual or family is constrained by a variety of conditions, among which the allocation of resources or wealth across the period is an important constraint. Therefore, it is particularly important to study the field of consumer finance in China. The purpose of this paper is to discuss the basic categories and main issues of consumer finance and summarize the development of consumer finance in China. On this basis, from the family financial activities, consumer behavior and consumer finance, consumer finance and the financial market and the relationship between the government and other aspects of combing, further combined with the actual situation in China to open the two children in an all-round way, put forward the future research direction of China's two child consumer finance field.

\section{THE BASIC CATEGORIES OF CONSUMER FINANCE}

Academically, there is no clear definition of the content and category of consumer finance. The main reason is that consumer finance involves many aspects, such as economy, finance, psychology, behaviourology, sociology and other related fields. Secondly, consumer finance is a new research field. So this paper tries to give consumer finance a more comprehensive and complete concept and framework from the recent research.

\section{A. Concepts and terms related to consumer finance}

Starting from the consumption subject of consumer finance research, the concept of consumption based on individual or family is more specific than consumer concept. The following are the following:

Consumer finance: it mainly defines the scope of research from the perspective of consumers' financial needs. The demand for finance includes consumer's consumption goals, savings, investment, credit, asset allocation, and various risks and constraints facing them. Tufano [1] defines the scope of consumer finance in terms of various financial functions that consumers need. He divides the function of consumer finance into four aspects: the first is payment, such as cheque, payment card, credit card and so on; the second is risk management, such as life insurance, preventive savings, etc.; third is credit, such as home mortgage, educational loan, etc. fourth is savings and investment, such as basic gold, bond and so on. Wang Jiang [2] broadened the meaning of consumer finance in two aspects. First, consumption in consumer finance includes consumption in daily life, including the use or consumption of non productive purposes of all resources; second, the financial functions, financial environment, policy environment, and other financial technologies, products, services, laws, regulation, policies and policies needed by consumers are included in the consumer finance. To the research of consumer finance. From the above description, we can find that consumer finance is a broad concept. Scholars' research is also inadequate but they can complement each other. Taking consumers as the main body of consumption, it is more abstract and general. 
Family finance: Campbell (2006) proposes to study financial activities based on family investment decisions and family consumption decisions. First, the family is not necessarily an economic unit, but the decision of the individual is often constrained by the family. At the same time, the decision of the family as a whole is the result of the choice of each member of the family. In this way, family finance is included in the category of consumer finance.

\section{B. Other aspects of consumer finance}

Important social indicators show that social progress and quality of life can be measured objectively and subjectively. In consumer finance, important objective indicators include consumer income, expenditure, debt, assets and various combinations of these indicators. These indicators are all related to consumption: income can be used for both current and future consumption. Expenditure is a measure of current consumption. Debt is used to provide funds for current consumption, and assets are accumulated to ensure future consumption. Another important objective indicator of consumer finance is consumer finance, which is parallel to the main consumer financial indicators, including income, expenditure, lending and savings. The ability to perform appropriate financial actions and adequate financial knowledge to achieve an ideal financial goal is considered to be the financial capability of consumers. When the ideal level of these indicators is achieved, the financial situation will be achieved. Financial benefits can also be measured by subjective measures, such as satisfaction with financial satisfaction and other financial indicators, such as income, expenditure, borrowing and savings. As an important field of life, consumer finance is closely related to subjective well-being such as quality of life, happiness and life satisfaction.

To sum up, we can see: first, from the subject of consumption, the main object of consumer finance research is individual and family; second, financial environment, government behavior, and consumer related financial products and services should also be included in the study of consumer finance; third, consumer finance refers to consumption. Various financial activities, including the payment of credit, savings, investment, insurance, trust and so on. Fourth, some objective indicators in the research of consumer finance have also been used in the field of social progress, quality of life, happiness and other social and life fields. Of course, as a new research field, the scope and content of consumer finance will continue to expand and develop.

\section{THE THEORETICAL DESCRIPTION OF CONSUMER FINANCE}

Consumption has early and late points, consumption or early or late are two different kinds of goods. The consumption intention of people can be changed in life. The most basic theory of consumer finance is Modigliani (1954)'s life cycle theory. Based on the rational choice theory and the rational expectation hypothesis, this theory holds that the individual determines the consumption of each period according to the wealth and income of the whole life cycle under rational expectation in order to maximize the total utility. The mathematical model of consumer decision-making in this theory is as follows:

$$
\operatorname{MAX}\left[E\left\{\sum_{t=o}^{T} \beta^{t} u\left(c_{t}\right)+\beta^{T+1} V\left(W_{T+1}\right)\right\}\right]
$$

In formula (1), $E\{\}$ represents expectation, $\beta$ represents its time preference rate, $u()$ is the utility function of consumers, $C_{t}$ represents the current consumption of decision-makers, $\mathrm{Wt}+1$ refers to the wealth left over at the end of the life cycle (that is, the market value of net assets), $V()$ represents the efficiency function of the decision maker to the heritage. Consumers will also be subject to dynamic budgetary constraints in the course of decision-

$$
\begin{gathered}
\text { making. } W_{T+1}=\left(W_{t}+Y_{t}-C_{t}\right)(1+r)(\mathrm{r}=0, \\
1 \ldots \mathrm{T}), W_{T+1} \geq 0
\end{gathered}
$$

In formula (2), $W_{t}$ is the wealth or net assets of the current period. $Y_{t}$ is the current income and $r$ is the interest rate. (2) the meaning of the formula is that the current net income is deducted from current consumption, that is, net savings in the current period. If savings are negative, it represents loans. These savings and the original wealth together with the interest earned together form the wealth of the next period. Moreover, the wealth left by decision-makers in the last life cycle is. $W_{T+1} \geq 0$ The consumer decision problem described by formulas (1) and (2) takes into account the choices now being made for consumption and future consumption, through savings or borrowing. Although it is simple, it reflects the three most basic financial implications in consumer decision-making: first, the core of the decision is the allocation of resources across the period; second, the configuration is accomplished through the financial market, if there is no savings and lending opportunities provided by the market, and the allocation is very difficult for the period; third, the configuration is to a great extent. It depends on the situation of the market, that is, interest rates. Therefore, the consumption of individual or family can be adjusted in the financial market, and the environment of the financial market and the design of financial products have become the limiting conditions for individual or family consumption. 
In relation to consumption and interest, Fisher, (1867-1947) made another important contribution. He thinks that from a teenager to an elderly person, his intention to consume can be changed. It can be summed up in the following three kinds: the first is like Li Bai, "wine today, drunk today, tomorrow to worry about tomorrow", this kind of person likes high consumption when young, old and then plan; the second is like Qi Baishi, when young, every penny is calculated, never chaotic, to the old when the home is million; the third is his whole life. Cyclical consumption is a bit of a dull thing. Zhang Wuchang also added a situation, fourth kinds, in his entire life cycle consumption like waves, ups and down, sometimes luxurious and hungry. According to Fisher's view, no matter what one's desire for his own consumption is described above, the person's consumption should not be influenced by the pattern of its living income. This is because there is a lending market that can spend money or money. In this way, Fisher gets an important conclusion: as long as the wealth is the biggest occupation after the discount of income discounted, the person's consumption should not be affected by the pattern of its living income.

Therefore, the consumption of individual or family can be adjusted in the financial market, and the environment of the financial market and the design of financial products have become the limiting conditions for individual or family consumption.

\section{THE PRESENT SITUATION OF THE DEVELOPMENT OF CHINA'S CONSUMER FINANCE}

In 2010, the party put forward a long-term mechanism to expand consumption demand in the fifth Plenary Session of the 17th CPC Central Committee. In March 2011, "the outline of the national economy and social development", which was published in March 2011, proposed that in the next 5 years, China should take the expansion of consumption demand as the strategic focus of expanding domestic demand, set up a longterm mechanism to expand consumption demand, and achieve the goal of increasing the consumption rate of residents. According to the data from the National Statistical Bureau of People's Republic of China in 2017, the final consumption expenditure of China in 2010 was 19 trillion and 700 billion yuan, accounting for $48.5 \%$ of GDP. By 2016, the final consumption expenditure was 33 trillion yuan, accounting for $53.6 \%$ of GDP. In 2010, all the people in our country consumed 10919 yuan, with 1978 as the base period. The consumption level index of the residents was 1124.5; in 2016, the per capita consumption of our country was 21228 yuan, with 1978 as the base period, and the consumption level index of all residents was 1816.1. According to the statistics of the people's Bank of China, by December 2017, household loans reached 40 trillion and 500 billion yuan, accounting for 33.8\% of the entire domestic loan, of which short-term consumer loans reached 6 trillion and 800 billion yuan, medium and long term consumer loans reached 24 trillion and 700 billion yuan, and consumer loans accounted for $76 \%$ of household loans. According to the above data, we can see that the overall consumption expenditure and the per capita consumption level of the residents are improving, the volume of household loans is large, and the proportion of consumer loans is as high as
$76 \%$. Therefore, consumer finance plays a major role in the allocation of resources of residents.

At the national policy level, the people's Bank of China promulgated the related management methods of housing loans, automobile consumption loans and personal consumption credit around 1999. In 2007, China began to pilot consumer finance in Guangdong area. In 2009, China introduced the "pilot management measures for consumer finance", allowing a Consumer Finance Companies to set up a Consumer Finance Companies in Beijing, Shanghai, Tianjin and Chengdu respectively. In November 2013, the CBRC revised the management "measures for the pilot project of consumer finance". In June 2015, Premier Li Keqiang of the State Council convened a standing meeting of the State Council and decided to expand the Consumer Finance Companies pilot to the whole country. This policy pointed to a great increase in the driving force of consumption to the economy in June 2015.

\section{THE STATUS QUO OF THE IMPLEMENTATION OF THE POLICY OF TWO CHILDREN IN CHINA}

According to the 2010 "six popular" data published by the People's Republic of China National Bureau of statistics, the proportion of the aged 60 and above has reached $13.26 \%$, and the proportion of children at the age of $0-14$ is $16.60 \%$. According to the statistics published by the National Bureau of statistics, the data of the 2017 "National economic and social development statistics bulletin". The proportion of the aged 0 and above has reached $17.3 \%$, and the proportion of children at $0-15$ is $17.80 \%$. The birth rate of the population in 2010 is $11.90 \%$, the natural population growth rate is $4.79 \%$, the birth rate of the population is $12.43 \%$ in 2017 , and the natural population growth rate is $5.32 \%$. It can be seen that the degree of aging in China is becoming more and more serious. The new normal population of China has four characteristics, one is that the fertility rate is low for a long time, the two is that the aging is becoming more and more serious, the three is the rising of urbanization, and the four is the tendency to be frequent. Under this new normal, we must solve the cold problem of the two child policy with a completely new way of thinking. Therefore, we can see that the implementation of the two child policy is not the main reason that restricts the family's two children.

\section{CONCLUSION}

Our country has implemented a policy of fully opening the two child policy and no longer restrains the birth of two children by individuals or families, but the allocation of existing resources and future resources is still a limited constraint on the two children of individuals or families, and we hope to study the impact of consumer finance on individual or family fertility two children. It can reduce the constraints in this area, allowing individuals or families to have more free choice in the two child bearing. Finally, on the basis of the previous discussion, this paper puts forward some views on the research on the two - child policy of consumer finance in China, and especially hopes to explore the challenges we face and the direction of development. 
First, we understand the content of consumer finance as a study of how consumers achieve their goals through intertemporal allocation of resources. What is the goal? In the life cycle theory, family goals are set to maximize consumption utility. But this goal hypothesis is still questionable. Recent experiments and empirical studies have shown that there are some differences between the actual economic and financial behavior of individuals and the scenario described by the expected utility function in the classic financial economics. In this direction, we can find new directions in the study of two children in China.

Second, the financial institutions, the Consumer Finance Companies and the e-commerce platform providing consumer financial services, in the design of consumer financial products and services, need more consideration of the reality of family birth of two children in our country, in order to design better products and services.

Third, the study of the whole consumer financial market environment and the government policy should be combined with the reality of two children in our family, including education, medical treatment, insurance and other policies.

\section{REFERENCES}

[1] Tufano P. "Consumer Finance," J. Annual Review of Financial Economics, pp. 227-247, 2009.

[2] Wang Jiang, Liao Li, Zhang Jinbao. "A summary of the research on consumer finance,” J Economic Research Journal, pp. 5-29, 2010.

[3] Devaney S A. "Handbook of consumer finance research," M. Springer New York, 2008.

[4] Zhu F X, Wymer W, Chen I. "IT-based services and service quality in consumer banking," J. International Journal of Service Industry Management, pp. 69-90, 2002.

[5] Devaney S A. "Handbook of Consumer Finance Research," J. Journal of Financial Counseling \& Planning, pp. 19, 2008.

[6] Li Yanqiao. "Restrictive factors and Countermeasures of China's consumer finance development," J. Shandong Social Sciences, pp. 149153, 2014.

[7] Xie Ping, Zou Chuanwei. "Research on the Internet financial model," J. Economic Research Journal, pp. 11-22, 2012.

[8] Zhang Ran. "Research on the influencing factors of 'two child' new deal effect -- from the perspective of family consumption," J. Consumer Economics, pp. 83-87, 2014. 